\title{
Exploring the Effects of the Health Cloud Platform Management Service System Combined with the Grid Partition Grading Supervision for Controlling COVID-19 in the General Hospital
}

\section{Mengsha Qi}

Department of psychology, Chengdu Medical College.

shuyun liu ( $\square$ lsy327@foxmail.com )

Chendu Wenjiang District People's Hospital https://orcid.org/0000-0001-6747-4903

\section{Yuchan Wang}

Chengdu Wenjiang district people's hospital

Jun Liu

Chengdu Wenjiang District People's Hospital

\section{Liguo Wu}

Chengdu Wengjiang District People's Hospital

Zhihui Liu

Chengdu Wengjiang District People's Hospital

\section{Xuehong Yu}

Chengdu Wengjiang District People's Hospital

\section{Research article}

Keywords: COVID-19, general hospital, Methods of prevention and control of nosocomial cross-infection

Posted Date: September 30th, 2020

DOI: https://doi.org/10.21203/rs.3.rs-55362/v1

License: (9) (i) This work is licensed under a Creative Commons Attribution 4.0 International License. Read Full License 


\section{Abstract}

Background: The study aimed to explores the effects that a new management method for prevention and control of COVID-19 in the general hospital.

Methods: The study conducted empirical research to explores the effect of the service system and the supervision in the prevention and control of COVID-19 in the general hospital in China.

Results: By comparing the efficiency, we can see that using the service system, combined with the grid partition grading supervision, can effectively prevent cross-infection in the hospital, protect the physical and mental health of medical staff.

Conclutions: Constructing the health cloud platform management service system combined with the grid partition grading supervision has a significant effect in preventing cross-infection in the hospital and protecting the physical and mental health of medical staff during the COVID-19 outbreak.

\section{Background}

The World Health Organization's (WHO) Director-General stated:"There have now been 11.4 million cases of COVID-19 and more than 535,000 lives have been lost.The outbreak is accelerating and we have clearly not reached the peak of the pandemic."

Recently, studies have found that the virus has mutated and evolved into subtypes with stronger infectivity, ${ }^{2,3}$ so it is difficult to eliminate completely in the short term; thus, there should be preparation for a protracted war against the virus.As one of the first batch of general hospital $s$ in China that has been facing COVID-19 outbreaks,we have researched a new cloud platform health management service system, combined with grid partition grading supervision, and found that it has achieved better results in preventing cross-infection in hospital, ensuring the physical and mental health of medical staff so as to effectively implement anti-epidemic work. The specific method is introduced as follows:

\section{Methods}

\section{Study design and participants}

The research focuses on the effective measures taken in crucial aspects such as preventing crossinfection in the hospital and ensuring the health of medical staff.

The study conducted empirical research to explores the effect of the service system and the supervision in the prevention and control of COVID-19 in the general hospital in China.

The specific research method and process are shown in Fig. 1.

\section{Results}


Different methods of collecting big data on health problems have had varying effects during the COVID19 outbreak.

At the initial stage of the epidemic, the information of each department was reported in confusion. During the first four days, the health status information of relevant personnel in the hospital was collected by each department using Excel. The effective rate of the information was only $25 \cdot 27 \%-42 \cdot 99 \%$ at the given time. Over the next three days, participants completed a network questionnaire survey to report their health status, and it became clear that previous data had been misreported, but there were still big drawbacks; the valid questionnaire showed that the values increased to $60 \cdot 03 \%-67 \cdot 81 \%$. Based on this, from February 5, 2020 to March 2, 2020, using the grid partition for grading supervision, the effective questionnaire became gradually more accurate and timely thanks, in part, to district supervisors' hierarchical supervision, information verification, and daily regular reminders. The results are shown in Figure 2.

\section{Discussion}

\section{The necessity of establishing the COVID-19 health cloud platform management service system combined with the grid partition grading supervision.}

Facing the epidemic outbreak, as one of the designated general hospitals, we quickly set up the hospital anti-epidemic command centre. There are several task groups under the command centre; they include: hospital infection management, medical treatment, logistics support, information publicity, quality supervision, among others. These groups carry out prevention and control work centring on the two main lines of "External Prevention" and "Internal Control".

"External Prevention" means the screening, isolation, and treatment of infectious diseases for these patients and their relatives who came to the hospital during the infectious disease outbreak. "Internal control" is aimed at all hospital medical staff and their relatives to prevent them from being infected and to maintain their health. External Prevention and Internal Control are the two main lines of anti-epidemic efforts made by the two vice presidents of the hospital, who are assigned responsibility for COVID-19 prevention and management.

Whether External Prevention or Internal control were used, it was necessary to have accurate health monitoring data to support the decision; statistics describing the situation are an important auxiliary of scientific decision-making. ${ }^{4}$ With this big data on health problems, services can be classified and stratified according to health conditions. However, supervisions were also needed to determine how effective the services were and whether the measures were appropriate. This was consistent with the arguments of Xuejiao Chen ${ }^{5}$ and other scholars who have recommended the supervision system. These 
researchers have obtained promising results in the practice of supervision in the negative pressure isolation ward by using surveillance video.

In order to implement full coverage supervision in the general hospital s, human and material resources must be considered. Grid division and hierarchical supervision are likely better solutions. In high-risk areas such as isolation wards, intensive care units, and fever clinics, monitoring videos can be used and assigned to several supervisors who have passed the professional training to be on-duty in shifts. In contrast, one supervisor can be responsible for 3-5 areas for personnel quarantined at home and who are medium and low risk.

With the assistance of the department and relevant leaders, the follow-up supervision task was completed through the establishment of a WeChat group, mobile video calls, and phone call follow-ups. The study also proves the practicability and value of the method through practice, a big data survey of health problems, and the observed change in efficiency.

\section{The core and key points of the system.}

The core of the "system" construction was around "timely detection of problems, targeted solutions of problems, and supervision to ensure the effect".

The key point was that it must be closely connected with the anti-epidemic command centre of the hospital and the subordinate task groups. It was an indispensable and important link in the entire antiepidemic work of the general hospital .

In the face of COVID-19 (an unknown novel viral disease with high transmissibility), although relevant government departments had issued a series of diagnosis, treatment, and prevention and control guidelines according to the characteristics of infectious diseases, the accumulated measures of hospital infection prevention and control were faced with severe challenges in practice, and there were still many difficulties to be solved in the practice of hospital infection prevention and control. ${ }^{6}$

The rapid establishment of a command centre in the hospital, the mobilization of all staff, and the division of responsibilities were very important for the orderly promotion of various prevention and control tasks. ${ }^{7}$ The use of epidemic prevention work to establish the health cloud platform management service system, combined with grid partition grading supervision, played a positive role in ensuring the implementation and effectiveness of various prevention and control tasks.

\section{Practical application effect analysis}

\section{This "system" has played an important role in the timely and accurate collection of relevant problems in anti-}




\section{epidemic work.}

We can see from Figure 2 that, in the early stage of the task, the big data survey of health problems was completed by the head of the department with Excel, and the effective rate was less than $43 \%$. This indicates that the staff and patients did not pay enough attention to the epidemic outbreak, and the investigation method might not be reliable. Efficiency increased when users switched to the network survey, were required to fill in their real name, and declared that they would be responsible for misreporting, but it was still not timely. We offer several reasons for this. First, during the Spring Festival holiday, many employees did not pay attention. On the other hand, the staff were busy fighting the epidemic and did not pay attention to browsing information; therefore, the effective rate of reporting on time still hovered around $60 \%$.

In view of the above reasons, the command centre decided to set up a supervision group. These members were made up of administrative staff. After the sub-division of the supervision group, the efficiency of the regular report of the big data of health problems became gradually more accurate and timely. However, supervisors also had found many problems that had affected employee satisfaction in the process of supervision. After investigation, the command centre decided to establish a COVID-19 health cloud platform management service system to improve the quality of service.

By collecting COVID-19 big data on health-related problems, the problems were classified and handed to the task group to solve, and the supervision group verified the effect of every task implementation. This is similar to Belgium's use of big data to build a cloud platform for control of emerging infectious diseases and to implement real-time monitoring of the isolation of suspected infected patients and close contacts; this was done so that the isolation measures could be effectively implemented on a large scale. Mobile platforms could also be used to achieve online medical treatment, reduce the risk of cross-infection in face-to-face contact, relieve public anxiety, and maintain people's health. ${ }^{8}$

\section{The "system" played a vital role in protecting the health of medical staff and avoiding cross-infection in the hospital.}

By 24:00 on 16 February 2020, China had reported a total of 3,084 confirmed cases among medical personnel, accounting for $4.37 \%$ of the total cases. ${ }^{9}$ Therefore, it is necessary to strengthen the protection of employees' health. Fully ensuring the occupational health and safety of medical personnel was one of the necessary links in the crucial stage of epidemic prevention and control. ${ }^{10}$

The COVID-19 health cloud platform management service system combined with the grid partition grading supervision was completed in order to find out the health status of employees and related patients in time, maintain their physical and mental health, and avoid cross-infection. For instance, when anti-epidemic work continued into the third week, some of the key departments and medical staff were dissatisfied due to the pressure, overload of work, lack of protection materials, and other problems. The 
area supervisor shall timely report to the person in charge of the internal control group, coordinate through the command centre, and make overall arrangements for shifting tasks for the staff of the hospital.

The leader indicated that responsible persons of related task groups should go to the front lines and have direct contact with infectious patients to solve their difficulties and make suggestions according to the data collection on health problems. For example, they suggested that the hospital provide protective equipment to front-line staff as required and strengthen self-protection knowledge training. They also suggested making arrangements to the room, and that the dual workers should take turns taking care of their elderly family members and children at home. Psychological counselling was offered to relieve their pressure, insurance was purchased for them to reduce worries about coverage, and other measures were taken to effectively stabilize the staff mood and ensure the occupational health and safety of medical staff.

\section{Deficiencies and next improvement plan}

This work has established that the COVID-19 health cloud platform management service system, combined with the grid partition grading supervision, can effectively promote prevention and control work, as well as ensure the quality of operation. However, it requires the supervisor to have a sense of responsibility, patience, be good at communication, and endure hardship. It also requires excellent knowledge and skills of prevention and control of infectious diseases, otherwise, it will affect the quality of supervision. In particular, the supervisor in charge of the high-risk area must pass strict training that offers knowledge and skills of nosocomial infection management after passing the examination showing they are competent; alternatively they may act as a nosocomial infection management expert. It is worth noting that the supervisor's work pressure was also very high, and they were in need of job rotation and stress relief in order to protect their physical and mental health.

In addition, in the health cloud platform management service system, if we can make full use of the hospital monitoring video to continuously monitor the public areas and key epidemic prevention departments, like the isolation ward, for 24 hours, we may be able to reduce the workload of supervisors on the patrol area and save manpower. Timely identification of problems can make up for manpower defects. This is also the follow-up research practice task of this study.

\section{Conclusion}

This study confirmed that using the health cloud platform management service system, combined with the grid partition grading supervision, can not only promptly and accurately collect epidemic information, but also identify other problems in anti-epidemic work in a timely manner. The grid partition grading supervision and the tracking of the problem-solving effect can effectively prevent cross-infection in the hospital, protect the physical and mental health of medical staff, and promote effective implementation in efforts to control the epidemic. 


\section{Declarations}

\section{Acknowledgements}

The authors would like to express our gratitude to the stuffs of Department of Hospital Infection and Information Management of China Chengdu Wenjiang District People's Hospital for their participation in the study.

\section{Funding}

The study was funded by the Sichuan Provincial Science and Technology Department (2020JDR0348). The funders were not involved in the specific research work of the project except to provide fund support.

\section{Availability of data and materials}

Datasets for the current study are not publicly available to protect the anonymity of the respondents.

\section{Author Contributors}

SL and MQ contributed equally to the manuscript. SL:conception and design of the study, acquisition of partial data, and critical revision of the manuscript. MQ\acquisition of partial data drafted the manuscript. YW『responsible for statistical analysis; JL, LW, ZL, and $X Y \rrbracket$ contributed to the effect of the new method practice and acquisition data. All authors provided critical review of the manuscript and approved the final draft for publication.

\section{Ethics approval and consent to participate}

The study was approved by the Ethics Committee of Wenjiang District People's Hospital of Chengdu (EC2020-007). Written informed consent was obtained from all participants.

\section{Competing Interests}

The authors declare no competing interests.

\section{Consent for publication}

Not applicable. 


\section{Author details}

1.Department of Science and Education of Wenjiang District People's Hospital of Chengdu, 611135, Sichuan Province, China

2.Department of psychology, Chengdu Medical College, Chengdu,610500, China.

\section{References}

1. WHO Director-General's opening remarks at the media briefing on COVID-19 - 7 July http://www.ehealth123.net/archives/4595. Released in 2020-07-7 by eking.

2. Tang X, Cui J, Lu J, et al. On the origin and continuing evolution of SARS-CoV-2. National Science Review, 036. https://doi.org/10.1093/nsr/nwaa036

3. Shen Z, Ren L, Li M, et al. Genomic diversity of SARS-CoV-2 in Coronavirus Disease 2019 patients. Clinical Infectious Diseases, 203, https://doi.org/10.1093/cid/ciaa203

4. Chen $\mathrm{X}$, He F, Zhang $\mathrm{H}$, et al. Strategies and practices for the prevention and control of COVID-19 in a military general hospital. Med J Chin PAPF, https://doi.org/10.14010/j.cnki.wjyx. 20200312.001

5. Chen X, Tian J, Li G, et al. Initiation of a new infection control system for the COVID-19 outbreak. Lancet. Infectious diseases, 2020.

6. Yao H, Su J, Du M, et al. Difficulties and countermeasures in the prevention and control of hospital infection during the epidemic of COVID-19. Chinese Journal of Nosocomiology 2020; 30(6): 801doi:10.11816/cn.ni.2020-200217

7. Li S, Wenzhi H, Liao H, et al. Emergency recommendation of novel coronavirus infection in hospitals. Chinese Journal of Evidence-Based Medicine 2020; 1-9.

8. Xiao D, He R, Zhang J, et al. Implications of Belgium's epidemic prevention and control measures on COVID 19. Social security research; $1-12$. http://kns-cnki--nethttp.cnki.scrm.qfclo.com:2222/kcms/detail/42.1792.F.20200313. 1536.002.html (Accessed 13 March 2020).

9. Wang Q, Su B, Su J, et al. Data analysis and prevention and control: Suggestions of medical staff infected with COVID - Med J Chin PAPF, 1-3. https://doi.org/10.14010/j.cnki.wjyx.20200306.002 (Accessed 11 March 2020).

10. Guo L, Wang Y, Zhu R, et al. Practical strategies of hospital infection prevention and control in COVID19 general hospital s in Wuhan. Chinese Journal of Nosocomiology, 1-6. http://kns--cnki-nethttp.cnki.scrm.qfclo.com:2222/kcms/detail/11.3456.R.20200311.1837.004.html (Accessed 13 march 2020).

\section{Figures}




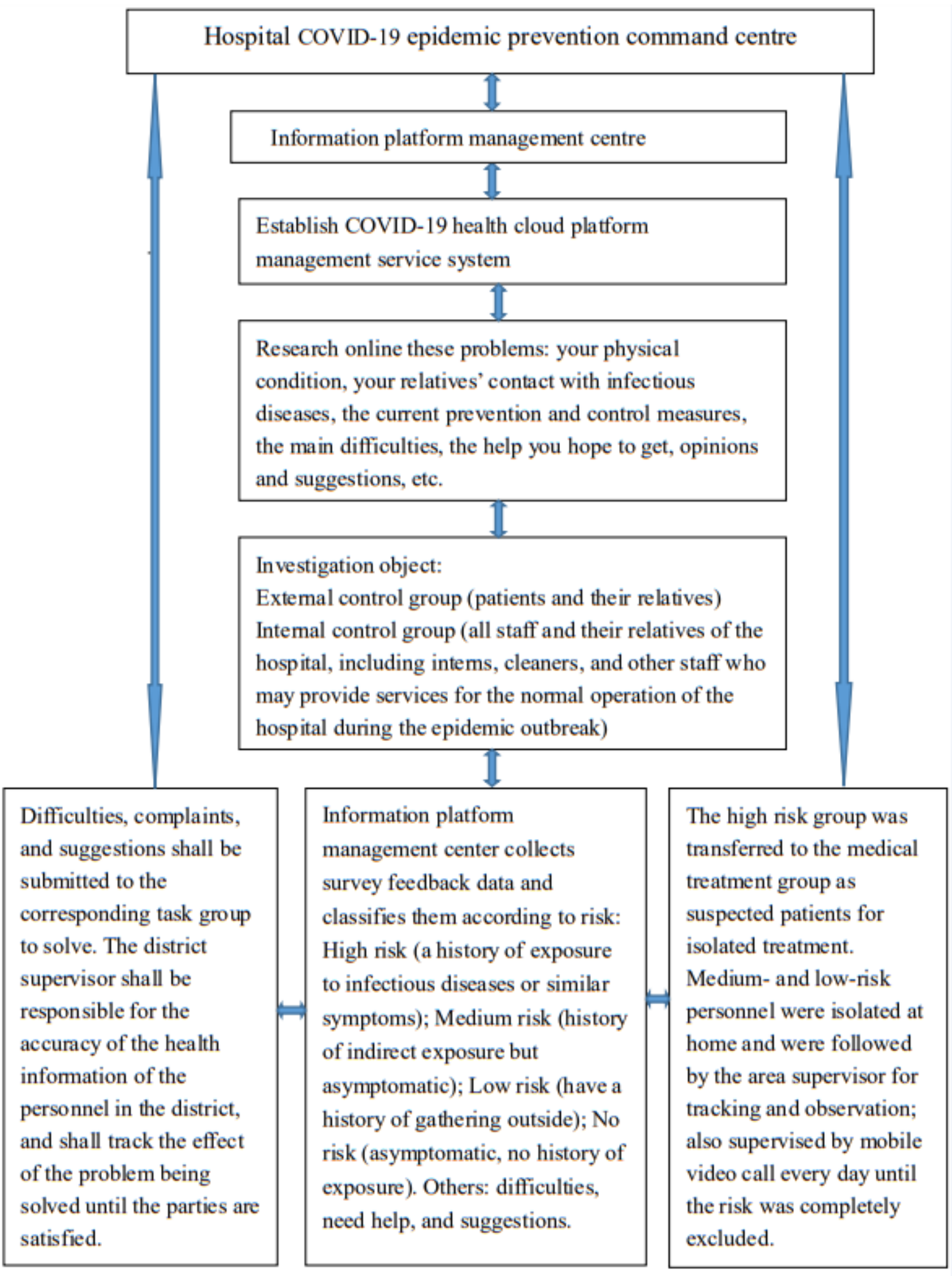

\section{Figure 1}

COVID-19 health cloud platform management service system with grid partition grading supervision operation flow chart 


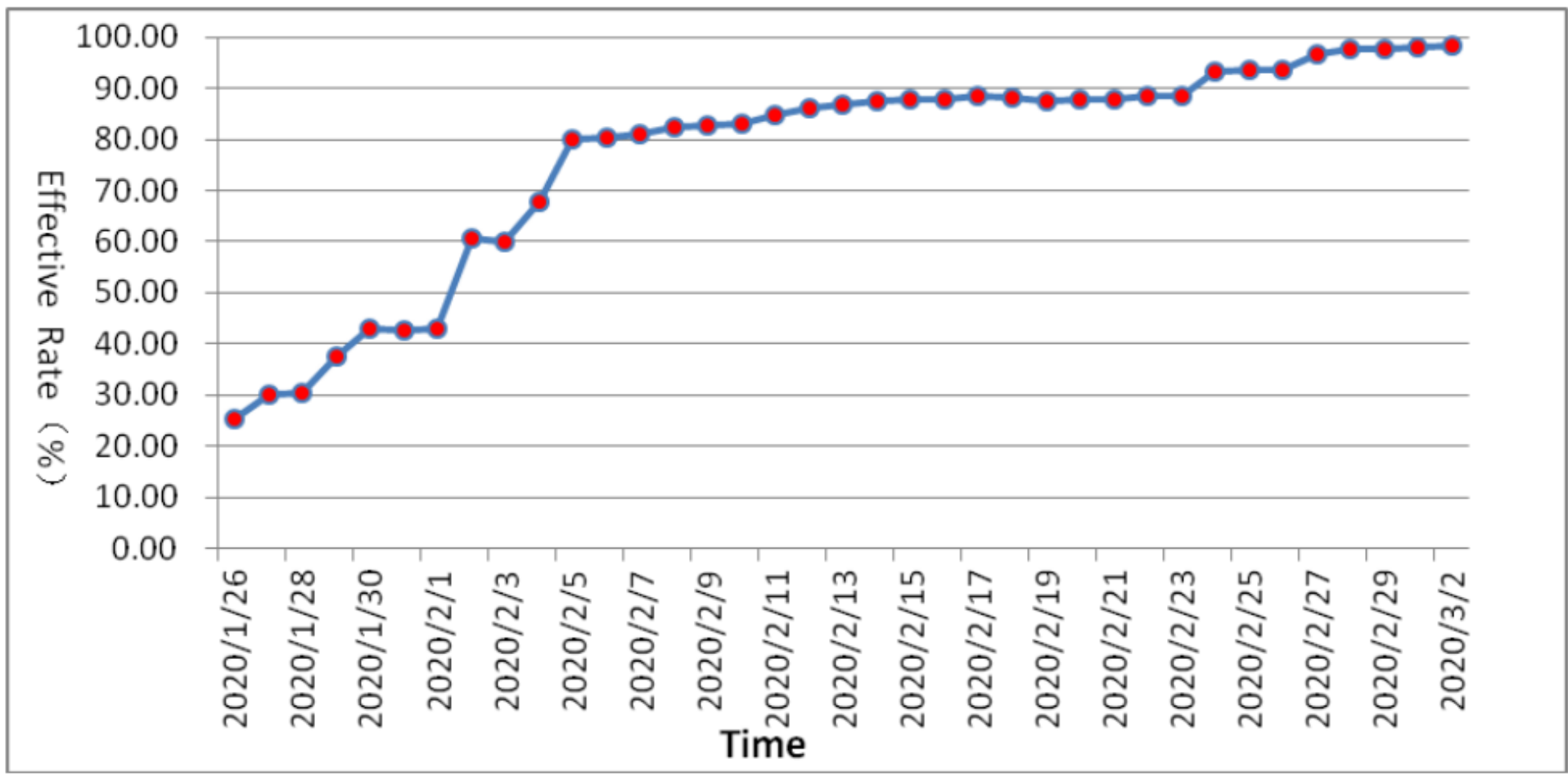

\section{Figure 2}

Efficiency changes in different methods of health problems, big data survey 